\title{
GF-3 SAR Ocean Wind Retrieval: The First View and Preliminary Assessment
}

\author{
He Wang ${ }^{1, *} \mathbb{D}$, Jingsong Yang ${ }^{2}$, Alexis Mouche ${ }^{3}$, Weizeng Shao ${ }^{4} \mathbb{D}$, Jianhua Zhu ${ }^{1}$, Lin Ren ${ }^{2}$ \\ and Chunhua Xie ${ }^{5}$ \\ 1 National Ocean Technology Center, State Oceanic Administration, Tianjin 300112, China; besmile@263.net \\ 2 State Key Laboratory of Satellite Ocean Environment Dynamics, Second Institute of Oceanography, State \\ Oceanic Administration, Hangzhou 310012, China; jsyang@sio.org.cn (J.Y.); renlin210@sio.org.cn (L.R.) \\ 3 Laboratoire d'Océanographie Physique et Spatiale, Institut Français de Recherche pour l'Exploitation de la \\ Mer, Brest 29280, France; alexis.mouche@ifremer.fr \\ 4 Marine Acoustics and Remote Sensing Laboratory, Zhejiang Ocean University, Zhoushan 316000, China; \\ shaoweizeng@zjou.edu.cn \\ 5 National Satellite Ocean Application Service, State Oceanic Administration, Beijing 100081, China; \\ chxie@mail.nsoas.org.cn \\ * Correspondence: wanghe_sio@126.com; Tel.: +86-22-2753-6515
}

Academic Editors: Xiaofeng Yang, Xiaofeng Li and Ferdinando Nunziata

Received: 4 June 2017; Accepted: 4 July 2017; Published: 5 July 2017

\begin{abstract}
Gaofen-3 (GF-3) is the first Chinese civil C-band synthetic aperture radar (SAR) launched on 10 August 2016 by the China Academy of Space Technology (CAST), which operates in 12 imaging modes with a fine spatial resolution up to $1 \mathrm{~m}$. As one of the primary users, the State Oceanic Administration (SOA) operationally processes GF-3 SAR Level-1 products into ocean surface wind vector and plans to officially release the near real-time SAR wind products in the near future. In this paper, the methodology of wind retrieval at C-band SAR is introduced and the first results of GF-3 SAR-derived winds are presented. In particular, the case of the coastal katabatic wind off the west coast of the U.S. captured by GF-3 is discussed. The preliminary accuracy assessment of wind speed and direction retrievals from GF-3 SAR is carried out against in situ measurements from National Data Buoy Center (NDBC) buoy measurements of National Oceanic and Atmospheric Administration (NOAA). Only the buoys located inside the GF-3 SAR wind cell $(1 \mathrm{~km})$ were considered as co-located in space, while the time interval between observations of SAR and buoy was limited to less the $30 \mathrm{~min}$. These criteria yielded 56 co-locations during the period from January to April 2017, showing the Root Mean Square Error (RMSE) of $2.46 \mathrm{~m} / \mathrm{s}$ and $22.22^{\circ}$ for wind speed and direction, respectively. Different performances due to geophysical model function (GMF) and Polarization Ratio (PR) are discussed. The preliminary results indicate that GF-3 wind retrievals are encouraging for operational implementation.
\end{abstract}

Keywords: GF-3; synthetic aperture radar (SAR); ocean surface wind; validation

\section{Introduction}

Space-borne synthetic aperture radar (SAR) sensors operating in C-band ( 5.3 GHz) have the capability to detect the sea surface at high spatial resolution under all-weather conditions, even in hurricanes. Normalized radar cross-section (NRCS) observations from SAR are directly related to the sea surface roughness of short surface waves. Therefore, assuming the surface wind is the first order contributor to these waves, coastal ocean surface winds at high resolution can be retrieved from SAR images. In recent decades, C-band SARs aboard Canadian satellite RadarSAT-1/2, and European satellites ERS-1/2, Envisat, and Sentinel-1A/B have demonstrated the capability of SAR to provide 
remote sensed ocean surface winds at a kilometer scale [1-3]. Moreover, these SAR-derived ocean surface winds are used in various applications, such as coastal wind energy resource assessment (e.g., [4]).

To date, Geophysical Model Functions (GMFs), which were originally developed to relate NRCS measured by scatterometers to ocean surface wind vector, are widely used for the estimations of ocean winds from C-band SARs. For VV-polarization, various empirical GMFs, describing the relationship between radar NRCS and the 10-m height ocean surface wind vector relative to radar viewing geometry, have been developed (e.g., [5-7]). When such GMFs are applied to HH-polarized SAR images, polarization ratio (PR) models have to be used to convert HH-NRCS into VV-NRCS before wind inversion. As for VV-GMF, different PR models have been developed (e.g., [8-10]). Studies indicate different performances depending on the GMF models (e.g., [11-13]). To date, ocean surface wind products derived from different satellite missions (scatterometers or SARs operating in C-band) rely on different GMFs. For instance, CMOD5.N [7] is currently used in MetOp-ASCAT scatterometer ocean wind processor; meanwhile, CMOD-IFR2 [6] is applied for the production of level 2 SAR ocean winds from Sentinel-1A/B [14]. Note also that different teams can use different GMFs. For instance, National Oceanic and Atmospheric Administration (NOAA) relies on a different GMF called CMOD5.H [15]. Thus, the choice of the GMF and PR models to be used for wind inversion is critical for GF-3 C-band SAR missions.

On 10 August 2016, carrying the first Chinese civil multi-polarization SAR operating at C-band, Gaofen-3 (GF-3) satellite was successfully launched into a polar sun-synchronous orbit of $755 \mathrm{~km}$ altitude with a 26-day repeat cycle. Following several months of in-orbit commissioning phase, GF-3 SAR has now been in operation since January 2017. Recently, a case of internal waves in the Yellow Sea captured by GF-3 was reported in Reference [16], implying promising marine application of the GF-3 SAR mission. As one of the primary users, the State Oceanic Administration (SOA) is operationally processing GF-3 SAR Level-1 products into Level-2 ocean surface wind vector and plan to operationally release the near real-time GF-3 SAR wind products. The aim of this paper is to present the first results of GF-3 SAR-derived winds and the preliminary assessment using the buoy measurements.

The remainder of the paper is organized as follows. Section 2 introduces the match-ups for GF-3 SAR images and in situ winds. Methodology for ocean wind retrieval with GF-3 SAR is presented in Section 3. The results of GF-3-derived winds and the assessment are given and discussed in Section 4. Finally, conclusions are given in Section 5.

\section{Description of Collocated Data Sets}

Validations of SAR-derived winds mostly lie on collocations with observations from buoys (e.g., [11]), offshore meteorological masts (e.g., [17-19]), and scatterometers (e.g., [3]). To date, besides HY-2A SCAT (exceeded its three-year design lifetime since 2015) providing degraded wind products, the available scatterometers are ASCATs onboard MetOp-A/B. Unfortunately, GF-3 and MetOp are in sun-synchronous orbits with the local equator crossing time at the ascending node of 6:00 am and 9:30 am, respectively. The large local time difference could limit the comparison of ocean winds derived from GF-3 and ASCATs. Hence, in this study, the validation of GF-3 wind retrieval was performed using in situ buoys.

\subsection{GF-3 SAR Data}

SAR data of high radiometric quality are essential for accurate ocean wind inversion. For GF-3 SAR, the external calibration campaign was carried out using active radar transponders deployed in Inner Mongolia, during the commissioning phase (from September to November 2016). The results from the in-orbit external calibration experiment reveal the NRCS radiometric accuracy of 1.3 1.4 dB $(3 \sigma)$, and Noise Equal Sigma Zero (NESZ) of -20 -22 dB [20] for different GF-3 SAR operating modes.

In this study, a total of 37 GF-3 SAR scenes were co-located with buoys over the period of January through April 2017. These GF-3 data have been collected in five GF-3 imaging modes (see Table 1 
for details) amongst the 12 modes of the sensor, including Standard Strip, Quad-Polarization Strip I, Quad-Polarization Strip II, Fine Strip I, and Narrow ScanSAR imaging mode with different polarization (dual-polarization or quad-polarization), pixel spacing, and SAR scene swath.

Table 1. Main parameters for GF-3 imaging mode used here.

\begin{tabular}{ccccc}
\hline $\begin{array}{c}\text { Imaging } \\
\text { Mode }^{1}\end{array}$ & Polarization & $\begin{array}{c}\text { Resolution } \\
(\mathbf{m})\end{array}$ & $\begin{array}{c}\text { Swath } \\
(\mathbf{K m})\end{array}$ & $\begin{array}{c}\text { Num of Synthetic Aperture } \\
\text { Radar Scenes Used }\end{array}$ \\
\hline SS & VV + VH or HH + HV & 25 & 130 & 26 \\
QPSI & VV + HH + VH + HV & 8 & 30 & 3 \\
QPSII & VV + HH + VH + HV & 25 & 40 & 5 \\
FSI & HH + HV & 5 & 50 & 2 \\
NSC & VV + VH & 50 & 300 & 1 \\
\hline
\end{tabular}

${ }^{1}$ SS, QPSI, QPSII, FSI and NSC stand for Standard Strip, Quad-Polarization Strip I, Quad-Polarization Strip II, Fine Strip I, and Narrow ScanSAR imaging mode of GF-3, respectively.

\subsection{Buoy Data}

Buoy measurements are generally assumed to be of high quality up to $30 \mathrm{~m} / \mathrm{s}[21,22]$ and hence were used as ground truth for the validation of wind retrieval from GF-3 SAR here. Wind observations of buoys have been collected from the National Data Buoy Center (NDBC) of NOAA. Most of them are off the west coast of the U.S., while some of them are in the region of Hawaiian Islands, southeast Pacific (Stratus buoy station), and Korean coastal sea.

In this study, only the buoys located inside the GF-3 SAR scene were considered as co-located in space. The buoy winds from NDBC are measured hourly by averaging the wind speed and direction over $10 \mathrm{~min}$. Therefore, the time interval between observations of SAR and buoy was limited to less the 30 min. During the period from January to April 2017, these criteria yielded 53 match-ups, whose locations are depicted in Figure 1.

Since the anemometers on the buoys measure the wind at different heights above the sea surface level, buoy wind speeds had to be converted to the equivalent neutral winds at $10 \mathrm{~m}$ for comparison between GF-3 retrieval and buoy measurements. Here, the correction was performed using the simple semi-rational formula of assuming a logarithmically varying wind profile [23]; the wind speed given at any elevation $\mathrm{z}$ can be calculated from the friction velocity $\mathrm{u}^{*}$ by:

$$
\mathrm{U}(\mathrm{z})=\frac{\mathrm{u}_{*}}{\mathrm{~K}} \ln \left(\frac{\mathrm{z}}{\mathrm{z}_{0}}\right)
$$

where $\mathrm{k}=0.4$ is the constant of von Kármán, and $\mathrm{U}(\mathrm{z})$ is the wind speed at a height of $z$. The friction velocity $\mathrm{u}^{*}$ is related to the sea surface roughness length $\mathrm{z}_{0}$ by [24]:

$$
\mathrm{z}_{0}=\frac{0.11 v}{\mathrm{u}^{*}}+\frac{\alpha \mathrm{u}^{* 2}}{\mathrm{~g}}
$$

Here, $\alpha=0.011$ is the Charnock parameter [23], $v\left(1.5 \times 10^{-5} \mathrm{~m}^{2} / \mathrm{s}\right)$ is the kinematic viscosity of air, and $\mathrm{g}$ is the gravitational acceleration. 

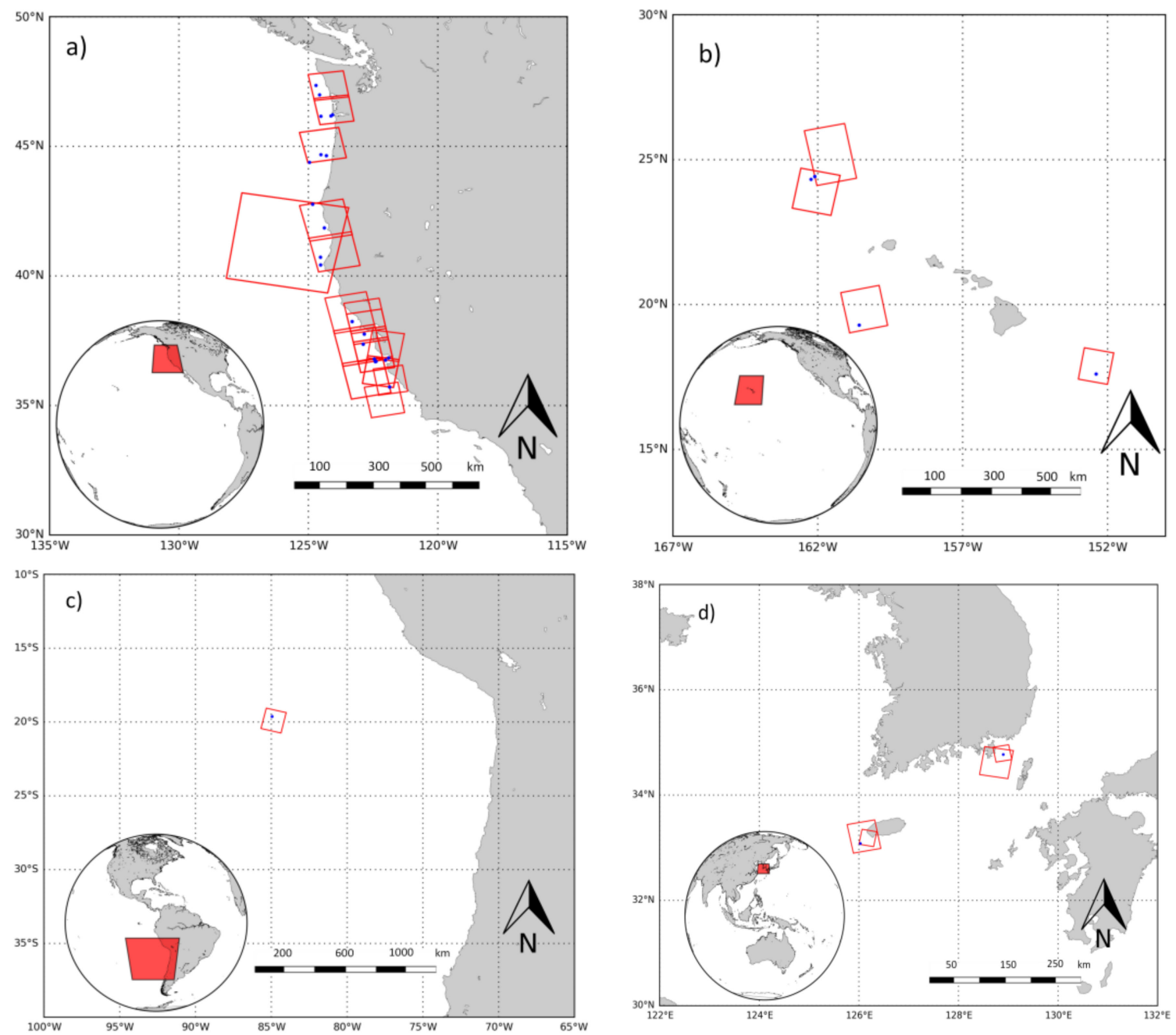

Figure 1. Map of footprints of GF-3 SAR acquisitions (red boxes) in the area of (a) U.S. west coast; (b) Hawaiian region; (c) South Pacific Ocean; (d) Korean coast. The blue dots denote the location of the National Data Buoy Center (NDBC) buoys.

\section{GF-3 SAR Wind Retrieval Scheme}

Both wind speed and direction could be inverted from NRCS measurements if multiple acquisitions over the same area are obtained simultaneously with different radar geometries, as for the scatterometers. In contrast, because SARs operate with only one radar viewing angle, the inversion of the NRCS leads to multiple solutions of wind vector. In this context, SAR wind retrieval schemes usually assume the wind direction as known from atmospheric models (i.e., [3,4]), or directly extracted from the SAR image if wind-induced streaks exist (i.e., [25]).

Before wind inversion, the pre-processing of GF-3 images requires radiometric calibration, land masking, and resampling of NRCS, incidence angle, and azimuth angle at a $1000 \mathrm{~m}$ resolution cell. The inversion methodology proposed here combines SAR NRCS with a priori wind from the European Centre for Medium-range Weather Forecasts (ECMWF) model, taking into account that both SAR observations and atmospheric models may contain errors [26,27].

In principle, in order to invert to the wind vector ( $\mathrm{u}, \mathrm{v}$ for two components), the cost function $\mathrm{J}(\mathrm{u}, \mathrm{v})$ defined as follows is minimized.

$$
\mathrm{J}(\mathrm{u}, \mathrm{v})=\left(\frac{\sigma_{\text {obs }}^{0}-\sigma_{\mathrm{GMF}}^{0}(\mathrm{u}, \mathrm{v})}{\Delta \sigma^{0}}\right)^{2}+\left(\frac{\mathrm{u}_{\text {model }}-\mathrm{u}}{\Delta \mathrm{u}}\right)^{2}+\left(\frac{\mathrm{v}_{\text {model }}-\mathrm{v}}{\Delta \mathrm{v}}\right)^{2}
$$


where $\sigma^{0}{ }_{o b s}$ is the calibrated GF-3 SAR NRCS at co-polarized channel (VV or HH). And $\mathrm{u}_{\text {model }}$ and $\mathrm{v}_{\text {model }}$ are the $\mathrm{U}, \mathrm{V}$ wind components from ECMWF model. These a priori winds provided from ECMWF at a $0.125^{\circ}$ spatial and a three-hourly temporal resolution were interpolated into the GF-3 wind retrieval cell at $1000 \mathrm{~m}$ resolution as $\sigma^{0}{ }_{\text {obs }} . \Delta \sigma^{0}, \Delta u$ and $\Delta v$ are the Gaussian standard deviation errors for the NRCS and the ECMWF model wind vector, respectively. $\sigma^{0}$ GMF is the NRCS prediction from the GMF model. A general form of GMF could be expressed in functions of second-order cosine harmonic, as below:

$$
\sigma^{0}=A_{0}\left[1+A_{1} \cos \varnothing+A_{2} \cos 2 \varnothing\right]^{B}
$$

where $A_{0}, A_{1}, A_{2}$ and $\mathrm{B}$ are the function of the 10-m-height wind speed and radar incidence angle, and $\varnothing$ is the wind direction relative to the radar look direction. For the HH channel, an additional PR model is used.

In order to make the inversion scheme more efficient, the minimization of cost function of Equation (3) is implemented with the help of the pre-computed look-up tables (LUT) from GMF models. Here, different LUT from models are used to test the GF-3 wind retrieval performance, including CMOD-like GMFs of CMOD-IFR2 adopted by Sentinel-1A/B and CMOD5.N used by MetOp-ASCAT, and PR models of Mouche et al. used by Sentinel-1A/B [9] and Zhang et al. [10]. Moreover, we also investigate the performances of C-band GMF called C-SARMOD recently proposed by Reference [28] for both VV- and HH-polarizations.

\section{Results and Discussion}

\subsection{GF-3 SAR Wind: The Case of Katabatic Wind}

Figure 2a shows a VV-polarized GF-3 SAR scene in Narrow Scan mode over the Californian coast. The image was acquired at 14:31 Universal Time Coordinated (UTC) (07:31 in local time) on 6 January 2017 , with an incidence angle ranging from $22^{\circ}$ (near range) to $37^{\circ}$ (far range). The wind field at $1000 \mathrm{~m}$ resolution retrieved from Figure $2 \mathrm{a}$ using the scheme proposed in Section 3 with the GMF of CMOD5. $\mathrm{N}$ is presented in Figure $2 \mathrm{~b}$.

In this case, brighter NRCS and corresponding higher sea surface wind speed are manifested along the coast, as shown in Figure 2a,b. This signature captured by GF-3 could be interpreted as the coastal katabatic wind. This kind of wind, blowing toward the coastal waters from the mountains, is the gravitational cold-air flow due to the temperature difference between the sea water and the shore. In addition to a meso-scale background wind, the katabatic wind increases the short surface waves, and thus the NRCS. This produces brighter areas near the coastline visible in SAR imagery as reported by References [29,30]. Compared with the ECMWF winds in $0.125^{\circ}$ grid, as shown in Figure $2 \mathrm{c}$, finer scale for the katabatic wind could be found the GF-3 wind retrievals in Figure $2 b$.

Three NDBC buoys are located inside this GF-3 SAR image, as the dots depicted in Figure 2a. For these three match-ups, ocean winds (speed at $10 \mathrm{~m}$ and direction) from GF-3 SAR retrieval and buoy observation are listed in in Table 2.

Table 2. GF-3 SAR winds against NDBC measurements for the case shown in Figure 2.

\begin{tabular}{cccccc}
\hline Buoy ID & $\begin{array}{c}\text { Latitude } \\
\left({ }^{\circ} \mathbf{N}\right) / \text { Longitude }\left({ }^{\circ} \mathbf{W}\right)\end{array}$ & $\begin{array}{c}\text { Buoy U10 } \\
(\mathbf{m} / \mathbf{s})\end{array}$ & $\begin{array}{c}\text { GF-3 U10 } \\
(\mathbf{m} / \mathbf{s})\end{array}$ & $\begin{array}{c}\text { Buoy Wind } \\
\text { Direction }\left({ }^{\circ}\right)\end{array}$ & $\begin{array}{c}\text { GF-3 Wind } \\
\text { Direction }\left({ }^{\circ}\right)\end{array}$ \\
\hline 46015 & $42.764 / 124.832$ & 6.16 & 6.1 & 143 & 150.4 \\
46027 & $41.852 / 124.382$ & 6.16 & 4.2 & 104 & 112.2 \\
46022 & $40.720 / 124.531$ & 7.2 & 5.2 & 114 & 145.5 \\
\hline
\end{tabular}



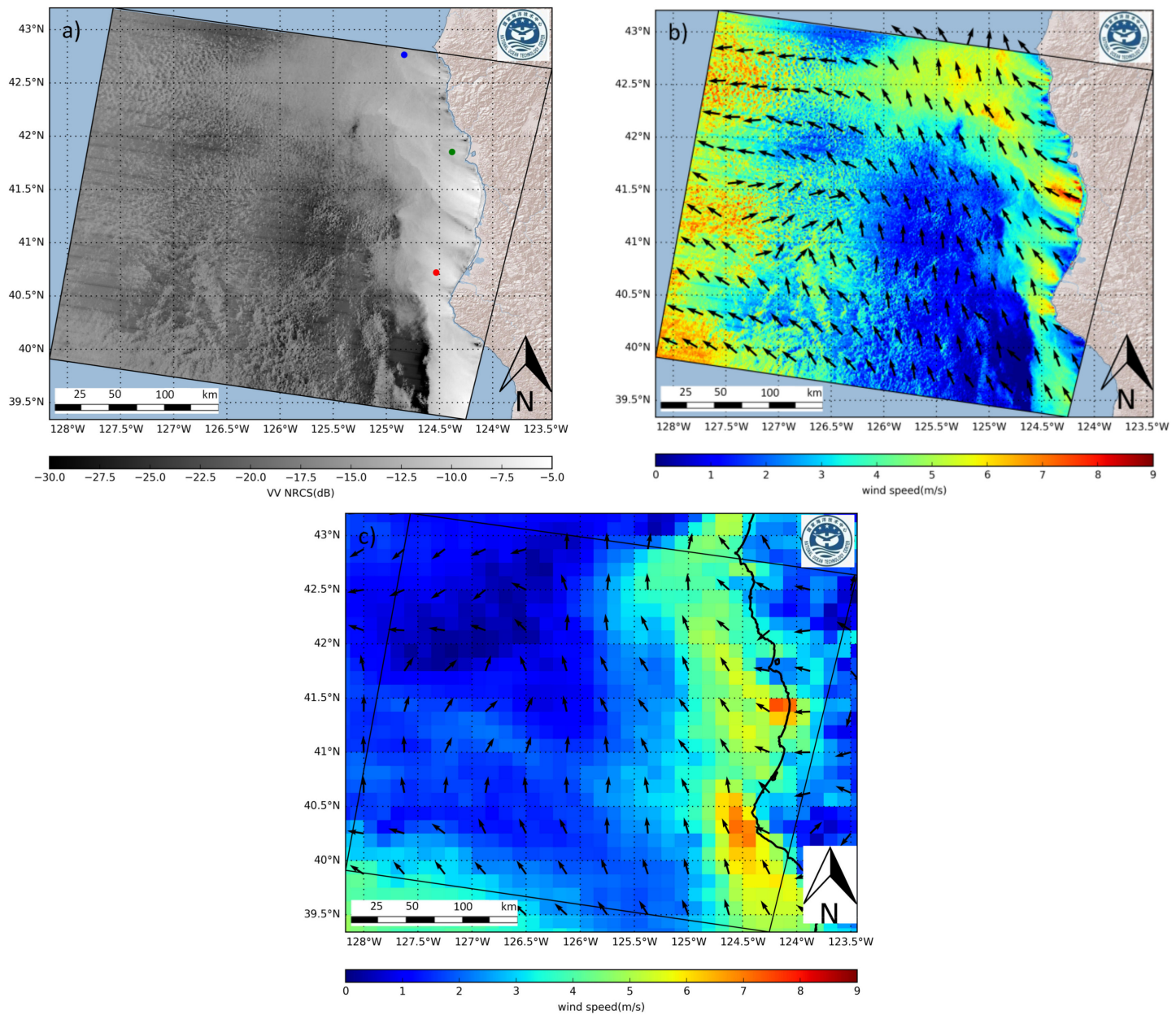

Figure 2. A katabatic wind case of GF-3 SAR image taken at 14:31 Universal Time Coordinated (UTC) (07:31 in local time) on 6 January 2017 in the Western U.S. coastal region: (a) Normalized radar cross-section (NRCS) at VV-polarization; (b) ocean surface wind inverted from VV NRCS using Geophysical Model Function (GMF) of CMOD5.N; (c) ocean surface wind from European Centre for Medium-range Weather Forecasts (ECMWF). The NDBC buoys of 46015, 46027, and 46022 are depicted as dots in blue, green, and red respectively.

\subsection{GF-3 SAR Winds from VV-Polarization}

For VV-polarization, 14 match-ups between GF-3 in SS, QPSI, QPSII, and NSC imaging mode and the buoys are found. In situ wind speed ranges between $5 \mathrm{~m} / \mathrm{s}$ and $15 \mathrm{~m} / \mathrm{s}$. The comparison of winds derived from VV-polarized GF-3 SAR using different GMFs against those measured from NDBC buoys are presented in Figure 3. In each scatterplot from Figure 3, colors represent the incidence angle of GF-3, ranging from $23^{\circ}$ to $45^{\circ}$. For wind speed, the application of GMF models of CMOD5.N, CMOD-IFR2, and C-SARMOD results in negative bias, with the smallest of $-0.15 \mathrm{~m} / \mathrm{s}$ using CMOD5.N for our retrieval. It is also shown that the Root Mean Square Error (RMSE) of the GF-3 retrieval of $10-\mathrm{m}$-height wind speed with respect to the buoy data is $2.34 \mathrm{~m} / \mathrm{s}, 2.60 \mathrm{~m} / \mathrm{s}$, and $2.53 \mathrm{~m} / \mathrm{s}$ using GMF models of CMOD5.N, CMOD-IFR2, and C-SARMOD, respectively. In terms of wind direction, a slight difference could be found for VV-polarization using the three GMFs, with bias and RMSE around $5^{\circ}$ and $21.9^{\circ}$, respectively.

Thus, among the three GMF models used, CMOD5.N shows the overall best performance for VV-polarized GF-3 SAR. 

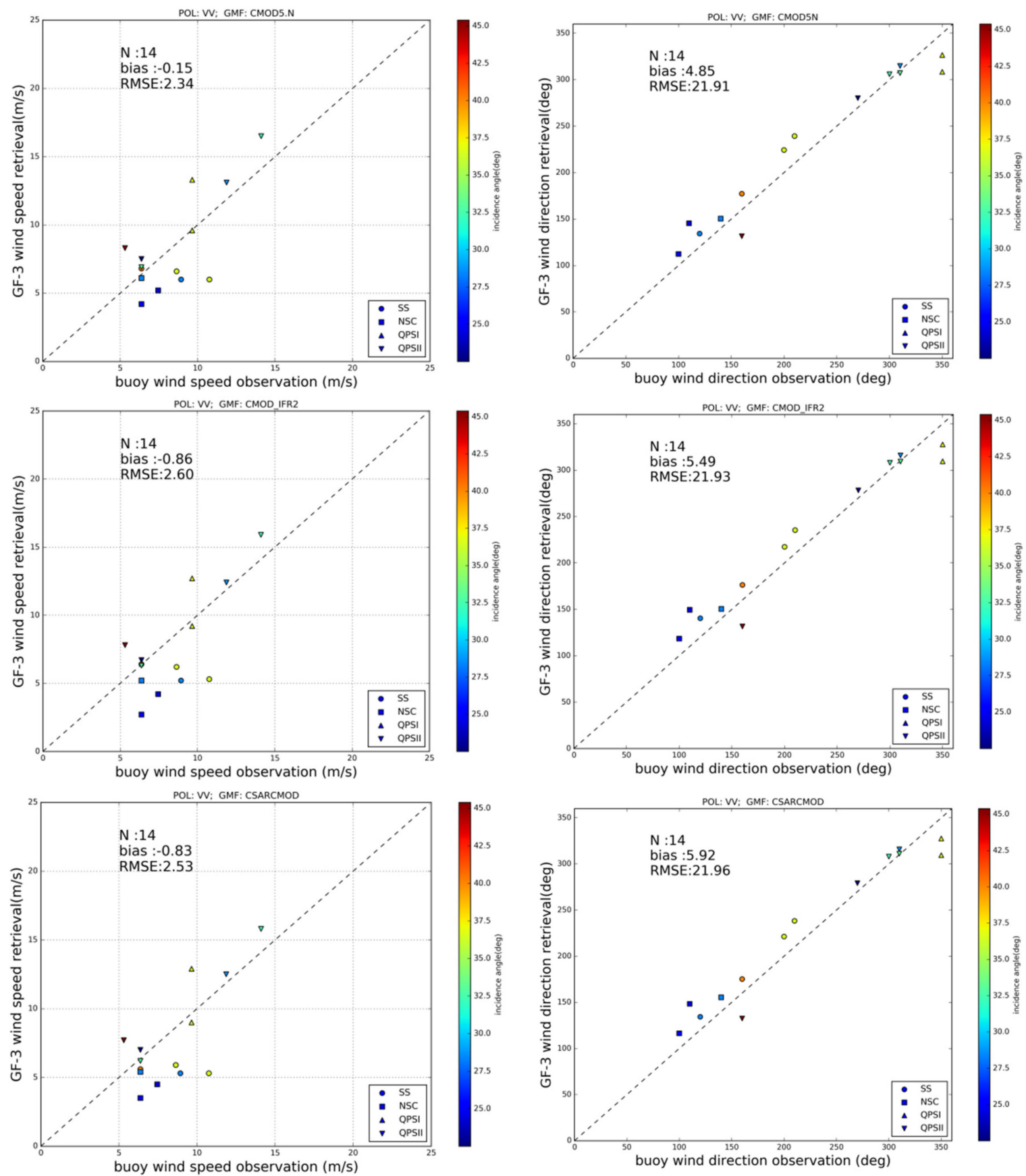

Figure 3. Scatter plots of wind retrievals from GF-3 SAR (VV-polarization) against NDBC buoy observations for wind speed (left panels) and wind direction (right panels). GF-3 winds estimated using GMF of CMOD5.N, CMOD-IFR2, CSARMOD_VV are presented from upper to bottom panels. Points with color indicate the incidence angle, and different markers present different imaging modes of GF-3, according to the legend.

\subsection{GF-3 SAR Winds from HH-Polarization}

Figure 4 illustrates the scatter plots of GF-3 SAR winds from HH-polarization against NDBC observations. Three different GMFs are used: CMOD5.N + PR model of Zhang et al. [10], CMOD5.N + Mouche et al. [9], and C-SARMOD for HH-polarization [28]. Respectively, 42 and 31 match-ups of HH-polarized wind retrievals against in situ buoys for wind speed and wind direction are compared here; some of the buoy wind direction data are missing. 

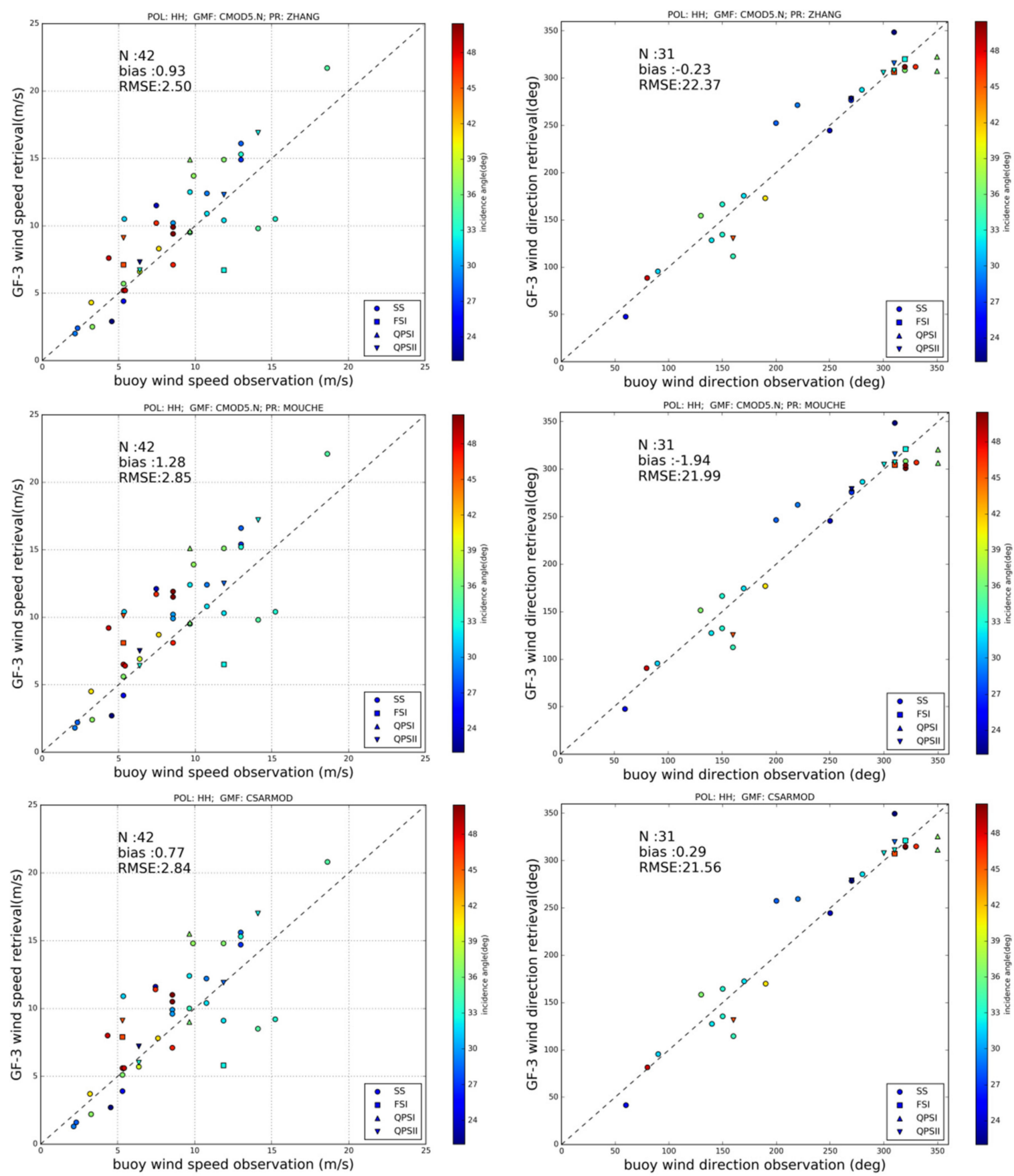

Figure 4. As in Figure 3, but for HH-polarized GF-3 SAR wind retrievals. GF-3 wind estimated using GMF of CMOD-5.N with of Zhang et al. [10], GMF of CMOD5.N with of Mouche et al. [9], and GMF of C-SARMOD_HH are presented from upper to bottom panels.

The wind direction retrievals show a slight difference for HH-polarization using the three GMFs. The RMSEs are very close between HH- and VV-polarized GF-3 retrievals, with a smaller bias for HH-polarized retrievals.

In terms of wind speed from HH-polarized GF-3 SAR, all the three GMFs used here present a positive bias. Also, larger RMSEs could be found compared to the results using CMOD5.N (see Figure 3) for VV-polarized SAR images, indicating that the GMF models used for HH-polarization could be improved in the future. Among the three models of GMF and PR applied to HH-polarized GF-3 SAR in this study, the combination of CMOD5.n and the PR model from Zhang et al. [10] leads to 
the smallest RMSE of $2.50 \mathrm{~m} / \mathrm{s}$, though the bias of $0.93 \mathrm{~m} / \mathrm{s}$ is a litter bit larger than the $0.77 \mathrm{~m} / \mathrm{s}$ of C-SARMOD. For the combination model of CMOD5.n and PR from Mouche et al. [9], and the empirical GMF C-SARMOD [28], very close RMSEs (around $2.85 \mathrm{~m} / \mathrm{s}$ ) could be found, while the latter GMF model presents smaller bias $(0.77 \mathrm{~m} / \mathrm{s})$ than those of the former $(1.28 \mathrm{~m} / \mathrm{s})$.

The new model of C-SARMOD is expressed by an explicit GMF so that the conversion of $\mathrm{HH}-$ to VV-polarization NRCS are no longer required, making it more applicable for HH-polarized SAR images. Although the smallest bias is found here, a larger RMSE is found for this new model, indicating that careful tuning may be needed in order to make it applicable for HH-polarized GF-3. Generally, the PR model proposed by Zhang et al. [10] illustrates good performances, due to the fact that it includes both the dependence of wind speed and incidence angle. Taking this into account for the preliminary comparison of different models, we selected the combination of CMOD5.n and PR model from Zhang et al. [10] for the HH-polarized GF-3 SAR wind retrieval in our scheme.

\subsection{GF-3 SAR Winds General Validation Statistics}

From the analysis in Sections 4.2 and 4.3, the GMF of CMOD5.N [7] and the PR of Zhang et al. [10] resulted in the best performance for the GF-3 wind retrieval scheme used here. As a consequence, they were chosen for the production of GF-3 ocean wind retrievals. Based on these GMF models, the GF-3 wind retrievals were assessed against NDBC winds, with the scatter plots depicted in Figure 5 and general statistics listed in Table 3. In general, an RMSE of $2.46 \mathrm{~m} / \mathrm{s}$ and $22.22^{\circ}$, and a bias of $0.66 \mathrm{~m} / \mathrm{s}$ and $1.35^{\circ}$ could be found for the comparison of GF-3-derived wind against buoy winds in this preliminary assessment.
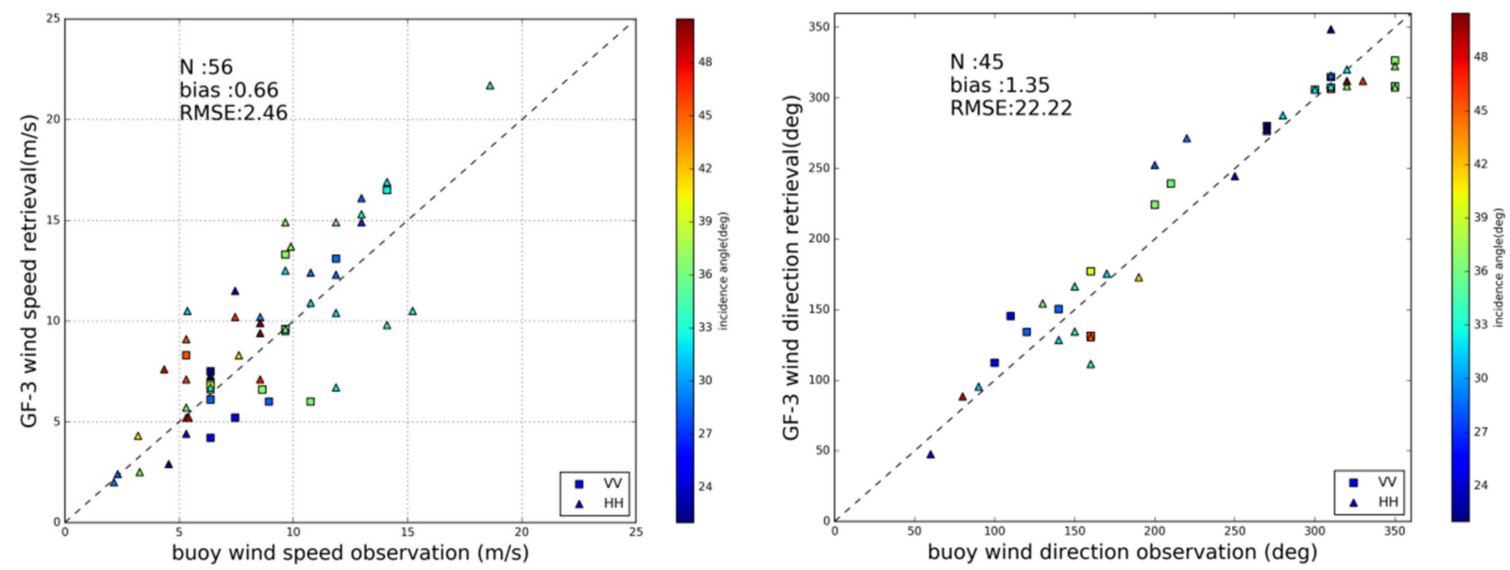

Figure 5. Scatter plots of GF-3 SAR wind retrievals against NDBC buoy observations for wind speed (left) and wind direction (right). GF-3 winds are estimated using the GMF of CMOD5.N and the PR of Zhang et al. [10], for HH-polarization. Points with color indicate the incidence angle, and different markers present different polarizations of GF-3, according to the legend.

Table 3. Statistics for GF-3 SAR winds against NDBC measurements.

\begin{tabular}{|c|c|c|c|c|c|c|c|}
\hline \multirow{2}{*}{$\begin{array}{c}\text { Polarization of } \\
\text { GF-3 Data }\end{array}$} & \multicolumn{3}{|c|}{ Wind Speed } & \multicolumn{3}{|c|}{ Wind Direction } & \multirow{2}{*}{ GMF Used } \\
\hline & $\mathbf{N}$ & $\operatorname{Bias}(\mathrm{m} / \mathrm{s})$ & RMSE (m/s) & $\mathbf{N}$ & Bias $\left(^{\circ}\right)$ & $\operatorname{RMSE}\left({ }^{\circ}\right)$ & \\
\hline \multirow{3}{*}{$\begin{array}{c}\text { All } \\
\text { co-polarization } \\
\text { VV } \\
\text { HH }\end{array}$} & 56 & 0.66 & 2.46 & 45 & 1.35 & 22.22 & \multirow{3}{*}{$\begin{array}{l}\text { VV: CMOD5.n } \\
\text { HH:CMOD5.n + PR model } \\
\text { from Zhang et al. [10] }\end{array}$} \\
\hline & 14 & -0.15 & 2.34 & 14 & 4.85 & 21.91 & \\
\hline & 42 & 0.93 & 2.50 & 31 & -0.23 & 22.37 & \\
\hline
\end{tabular}




\section{Conclusions}

In this paper, the proposed GF-3 SAR wind inversion methodology combines SAR-observed NRCS at a co-polarized channel with a priori wind information from ECMWF winds, taking into account that both NRCS observations and models may contain errors. In order to extract the wind speed and direction, the cost function is minimized with the help of look-up tables computed from geophysical model functions (GMFs), making the inversion scheme more efficient. Using this inversion scheme, coastal winds at $1 \mathrm{~km}$ resolution were estimated from the GF-3 SAR. One case of the coastal katabatic wind off the west coast of the U.S. captured by GF-3 is presented.

The first accuracy assessment of the ocean surface wind vector from GF-3 was carried out through a comparison with in situ observations from moored NDBC buoys, over the period from January to April 2017.

To select the GMF and PR models for the GF-3 wind inversion scheme, retrieval performances were compared for models including CMOD-like GMFs of CMOD-IFR2 and CMOD5.N, PR models of Mouche et al. [9], Zhang et al. [10], and the recently proposed C-SARMOD. The results indicate that the GMF of CMOD5.N and the PR of Zhang et al. [10] present the best performance for GF-3 wind inversion. Thus, these two models were chosen for the production of GF-3 ocean wind retrievals. A validation of GF-3-derived winds against NDBC measurements shows an RMSE of $2.46 \mathrm{~m} / \mathrm{s}$ and $22.22^{\circ}$ for wind speed and direction, respectively. These preliminary results indicate that GF- 3 wind retrievals are encouraging for operational products, which will be released from the State Oceanic Administration in the near future.

Future work will be dedicated to collect more data over buoys to increase the representativeness of our dataset and refine the performance assessment such as the error with respect to incidence angle, wind speed, or NESZ. In addition, the possibility of estimating the wind direction directly from GF-3 SAR images (e.g., [31]) will be investigated.

Acknowledgments: The GF-3 SAR data has been provided by the National Satellite Ocean Application Service in the framework of National High-Resolution Project of China via website of http:/ /dds.nsoas.org.cn/ (registration required), and we would like to thank Limin Cui and Wentao An for the GF-3 SAR data ordering and delivering. The authors are also grateful for the free access to buoy wind measurements provided by NDBC via http: / / www.ndbc.noaa.gov/. This work is supported by the National Natural Science Foundation of China (41506205), National Key R\&D Program of China (2016YFC1401003, 2016YFC1401007), National High-Resolution Project of China (Y20A14-9001-15/16) and Dragon-4 project (32249).

Author Contributions: He Wang wrote the manuscript; Alexis Mouche and He Wang devised and implemented the SAR ocean wind retrieval scheme; He Wang, Weizeng Shao and Lin Ren processed the GF-3 SAR data. All authors contributed to the discussion and revision of the manuscript.

Conflicts of Interest: The authors declare no conflict of interest.

\section{References}

1. Dagestad, K.-F.; Horstmann, J.; Mouche, A.; Perrie, W.; Shen, H.; Zhang, B.; Li, X.; Monaldo, F.; Pichel, W.; Lehner, S.; et al. Wind Retrieval from Synthetic Aperture Radar-An Overview. In Proceedings of the 4th SAR Oceanography Workshop (SEASAR 2012), Tromsø, Norway, 18-22 June 2012; pp. 1-24.

2. Horstmann, J.; Koch, W. Measurement of ocean surface winds using synthetic aperture radars. IEEE J. Ocean. Eng. 2005, 30, 508-515. [CrossRef]

3. Monaldo, F.; Jackson, C.; Li, X.; Pichel, W.G. Preliminary evaluation of Sentinel-1A wind speed retrievals. IEEE J. Sel. Top. Appl. Earth Obs. Remote Sens. 2016, 9, 2638-2642. [CrossRef]

4. Chang, R.; Zhu, R.; Badger, M.; Hasager, C.B.; Xing, X.; Jiang, Y. Offshore wind resources assessment from multiple satellite data and WRF modeling over South China Sea. Remote Sens. 2015, 7, 467-487. [CrossRef]

5. Stoffelen, A.; Anderson, D. Scatterometer data interpretation: Estimation and validation of the transfer function CMOD4. J. Geophys. Res. 1997, 102, 5767-5780. [CrossRef]

6. Quilfen, Y.; Chapron, B.; Elfouhaily, T.; Katsaros, K.; Tournadre, J. Observation of tropical cyclones by high-resolution scatterometry. J. Geophys. Res. 1998, 103, 7767-7786. [CrossRef] 
7. Hersbach, H. Comparison of C-band scatterometer CMOD5.N equivalent neutral winds with ECMWF. J. Atmos. Ocean. Tech. 2010, 27, 721-736. [CrossRef]

8. Thompson, D.R.; Elfouhaily, T.M.; Chapron, B. Polarization Ratio for Microwave Backscattering from the Ocean Surface at Low to Moderate Incidence Angles. In Proceedings of the 1998 Geoscience and Remote Sensing Symposium Proceedings (IGARSS'98), Seattle, WA, USA, 6-10 July 1998; pp. 1671-1673.

9. Mouche, A.; Hauser, D.; Daloze, J.F.; Guerin, C. Dual-polarization measurements at C-band over the ocean: Results from airborne radar observations and comparison with ENVISAT ASAR data. IEEE Trans. Geosci. Remote Sens. 2005, 43, 753-769. [CrossRef]

10. Zhang, B.; Perrie, W.; He, Y. Wind speed retrieval from RADARSAT-2 quad-polarization images using a new polarization ratio model. J. Geophys. Res. 2011, 116, C08008. [CrossRef]

11. Takeyama, Y.; Ohsawa, T.; Kozai, K.; Hasager, C.B.; Badger, M. Comparison of geophysical model functions for SAR wind speed retrieval in Japanese coastal waters. Remote Sens. 2013, 5, 1956-1973. [CrossRef]

12. Bergeron, T.; Bernier, M.; Chokmani, K.; Lessard-Fontaine, A.; Lafrance, G.; Beaucage, P. Wind speed estimation using polarimetric RADARSAT-2 images: Finding the best polarization and polarization ratio. IEEE J. Sel. Top. Appl. Earth Obs. Remote Sens. 2011, 4, 896-904. [CrossRef]

13. Liu, G.; Yang, X.; Li, X.; Zhang, B.; Pichel, W.; Li, Z.; Zhou, X. A systematic comparison of the effect of polarization ratio models on sea surface wind retrieval from C-band synthetic aperture radar. IEEE J. Sel. Top. Appl. Earth Obs. Remote Sens. 2013, 6, 1100-1108. [CrossRef]

14. Mouche, A. Sentinel-1 ocean wind fields (OWI) algorithm definition. In Sentinel-1 IPF Reference: (S1-TN-CLS-52-9049) Report; CLS: Brest, France, 2010; pp. 1-75.

15. Soisuvarn, S.; Jelenak, Z.; Chang, P.S.; Alsweiss, S.O.; Zhu, Q. CMOD5.H-A High Wind Geophysical Model Function for C-Band Vertically Polarized Satellite Scatterometer Measurements. IEEE Trans. Geosci. Remote Sens. 2013, 51, 3744-3760. [CrossRef]

16. Yang, J.S.; Wang, J.; Ren, L. The first quantitative remote sensing of ocean internal waves by Chinese GF-3 SAR satellite. Acta Oceanol. Sin. 2017, 36. [CrossRef]

17. Hasager, C.B.; Christiansen, M.B.; Peña, A.; Larsén, X.G.; Bingöl, F. SAR-Based wind resource statistics in the Baltic Sea. Remote Sens. 2011, 3, 117-144. [CrossRef]

18. Badger, M.; Badger, J.; Nielsen, M.; Hasager, C.B.; Peña, A. Wind class sampling of satellite SAR imagery for offshore wind resource mapping. J. Appl. Meteorol. Climatol. 2010, 49, 2474-2491. [CrossRef]

19. Beaucage, P.; Bernier, M.; Lafrance, G.; Choisnard, J. Regional mapping of the offshore wind resource: Towards a significant contribution from space-borne synthetic aperture radars. IEEE J. Sel. Top. Appl. Earth Obs. Remote Sens. 2008, 1, 48-56. [CrossRef]

20. Zhang, Q. System Design and Key Technologies of the GF-3 Satellite. Acta Geodaetica et Cartographica Sinica 2017, 46, 269-277. (In Chinese) [CrossRef]

21. Zeng, L.; Brown, R.A. Scatterometer observations at high wind speeds. J. Appl. Meteorol. 1998, 37, $1412-1420$. [CrossRef]

22. Weller, R.A.; Rudnick, D.L.; Payne, R.E.; Dean, J.P.; Pennington, N.J.; Trask, R.P. Measuring near-surface meteorology over the ocean from an array of surface moorings in the subtropical convergence zone. J. Atmos. Ocean. Technol. 1990, 7, 85-103. [CrossRef]

23. Charnock, H. Wind stress on a water surface. Quart. J. R. Meteorol. Soc. 1955, 81, 639-640. [CrossRef]

24. Smith, S.D. Coefficients for sea surface wind stress, heat flux, and wind profiles as a function of wind speed and temperature. J. Geophys. Res. 1988, 93, 15467-15472. [CrossRef]

25. Leite, G.C.; Ushizima, D.M.; Medeiros, F.N.S.; De Lima, G.G. Wavelet Analysis for Wind Fields Estimation. Sensors 2010, 10, 5994-6016. [CrossRef] [PubMed]

26. Portabella, M.; Stoffelen, A.; Johannessen, J.A. Toward an optimal inversion method for synthetic aperture radar wind retrieval. J. Geophys. Res. 2002, 107, 3086. [CrossRef]

27. Mouche, A.; Collard, F.; Chapron, B.; Dagestad, K.; Guitton, G.; Johannessen, J.A.; Kerbaol, V.; Hansen, M.W. On the use of doppler shift for sea surface wind retrieval from SAR. IEEE Trans. Geosci. Remote Sens. 2012, 50, 2901-2909. [CrossRef]

28. Mouche, A.; Chapron, B. Global C-Band Envisat, RADARSAT-2 and Sentinel-1 SAR measurements in copolarization and cross-polarization. J. Geophys. Res. 2015, 120, 7195-7207. [CrossRef]

29. Alpers, W.; Pahl, U.; Gross, G. Katabatic wind fields in coastal areas studied by ERS-1 synthetic aperture radar imagery and numerical modeling. J. Geophys. Res. 1998, 103, 7875-7886. [CrossRef] 
30. Li, X.; Zheng, W.; Pichel, W.G.; Zou, C.-Z.; Clemente-Colon, P. Coastal katabatic winds imaged by SAR. Geophys. Res. Lett. 2007, 34, L03804. [CrossRef]

31. Koch, W. Directional analysis of SAR images aiming at wind direction. IEEE Trans. Geosci. Remote Sens. 2004, 42, 702-710. [CrossRef]

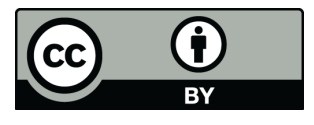

(c) 2017 by the authors. Licensee MDPI, Basel, Switzerland. This article is an open access article distributed under the terms and conditions of the Creative Commons Attribution (CC BY) license (http:/ / creativecommons.org/licenses/by/4.0/). 